\section{OP0138 RELATIVE GASTROINTESTINAL TOXICITY OF COX-2 SPECIFIC AND TRADITIONAL NSAIDS IN A HIGH-RISK POPULATION FROM A HEALTH MAINTENANCE ORGANISATION}

${ }^{1} \mathrm{D}$ Pettitt, ${ }^{2} \mathrm{JL}$ Goldstein, ${ }^{3} \mathrm{G}$ Singh, ${ }^{4} \mathrm{JS}$ Schwartz, ${ }^{5} \mathrm{TA}$ Burke. ${ }^{1}$ Outcomes Research, Pfizer Inc., NY, USA; ${ }^{2}$ Department of Gastroenterology, University of Illinois, Chicago, USA; ${ }^{3}$ Department of Medicine/Immunology, University of Stanford, Stanford, USA; ${ }^{4}$ Leonard Davis Institute, University of Pennsylvannia, Philadelphia, USA; ${ }^{5}$ Outcomes Research, Pharmacia Inc., Peapack, USA

\subsection{6/annrheumdis-2001.863}

Background COX-2 specific inhibitors (COX-2) are potentially prescribed to individuals at higher risk for adverse gastrointestinal (GI) outcomes, which produces "channelling" bias in nonrandomized observational studies. This bias may be minimised if the units of observation are the multiple drug exposure periods within high risk patients (ie individuals may be have both NSAID and COX-2 exposure periods).

Objectives To quantify the relative risk reduction of GI events associated with the use of COX-2 and traditional NSAIDs in a high risk cohort.

Methods All patients prescribed at least one COX-2 (celecoxib, rofecoxib) between $1 / 1-05 / 31 / 00$ were identified from a $\sim 3,000,000$ member health maintenance organisation. Using physician recorded primary diagnoses, the following endpoints were examined: nonhospitalized GI discomfort (abdominal pain, nausea, dyspepsia, ulcer diagnosis without endoscopy) \pm gastroprotective agent (GPA); and hospitalised or outpatient (with endoscopy) diagnosis of perforation, ulceration, or bleed (PUB). A multivariate Poisson regression model adjusting for the duration of drug exposure was used to compare the incidence of GI events associated with COX-2 or NSAID therapies ( $>200$ years exposure). The analysis adjusted for traditional GI risk factors (age, gender, arthritis diagnosis, comorid disease, GI history, drug dosing, concomitant GPA therapy, history of cardiovascular disease, corticosteroid therapy).

Results The cohort consisted of 22,696 patients who received a total of 2,853 and 6,519 years of NSAID and COX-2 exposure, respectively. The patient demographics were: $33.8 \%$ male; $47 \%$ osteoarthritis; $12.4 \%$ rheumatoid arthritis; $28 \%$ GI history; $25 \%$ history of gastroprotective agent use; and 63.3 years of age. After adjusting for significant risk factors $(\alpha=0.05)$, the relative risk reductions associated with COX-2 (bold) or NSAID therapy, using ibuprofen therapy as the standard, were as follows:

\begin{tabular}{llll}
\multicolumn{5}{l}{ Abstract } & OP0138 Table $\mathbf{1}$ \\
& $\begin{array}{l}\text { Patient-years } \\
\text { exposure }\end{array}$ & $\begin{array}{l}\text { RR vs ibuprofen GI } \\
\text { discomfort }(95 \% \mathrm{Cl})\end{array}$ & $\begin{array}{l}\text { RR vs ibuprofen } \\
\text { Confirmed PUB }(95 \% \mathrm{Cl})\end{array}$ \\
\hline $\begin{array}{l}\text { Oxaprozin } \\
\text { Nabumetone }\end{array}$ & 339 & $0.99(0.86-1.13)$ & $1.67(0.74-3.79)$ \\
Naproxen & 615 & $0.90(0.77-1.06)$ & $1.65(0.69-3.94)$ \\
Other & 712 & $0.97(0.87-1.09)$ & $1.23(0.60-2.50)$ \\
NSAIDs & & $0.95(0.85-1.06)$ & $1.12(0.55-2.29)$ \\
Diclofenac & 475 & $1.16(1.03-1.31)$ & $0.80(0.35-1.80)$ \\
Ibuprofen & 474 & 1.00 & 1.00 \\
Rofecoxib & 1344 & $\mathbf{0 . 8 0}(\mathbf{0 . 7 2 - 0 . 8 9 )}$ & $\mathbf{0 . 6 8}(0.33-1.40)$ \\
Celecoxib & $\mathbf{5 1 7 5}$ & $\mathbf{0 . 7 7 ( 0 . 7 0 - 0 . 8 5 )}$ & $\mathbf{0 . 5 3 ( 0 . 2 9 - 0 . 9 9 )}$ \\
\hline
\end{tabular}

Conclusion Consistent with clinical trial results, improved GI tolerability and safety is associated with the utilisation of COX-2 therapy compared to NSAIDs.

\section{SAT0228 THE FREQUENCY AND OUTCOME OF CARDITIS IN ACUTE RHEUMATEC FEVER}

B Heidari. Department of Medicine, Shaheed Beheshti Hospital Babol University of Medical Sciences, Babol, Iran

\subsection{6/annrheumdis-2001.86}

Background In spite of rarity in many areas, acute rheumatic fever (ARF) continues to be one of the most causes of valvular heart disease in the developing countries.

Persistence of residual heart disease depends on the severity of carditis at the time of acute attack and the frequency of subsequent recurrences.

Objectives To determine the frequency and the outcome of carditis in ARF, medical records of patients with ARF diagnosed in Shaheed Beheshti hospital from 1985-1990 were reviewed.

Methods All admitted and referral patients satisfying the modified Jones criteria for the diagnosis of ARF with follow up period over than one year included the study.

Diagnosis of carditis was based on physical findings and auscultation. Presence of residual heart disease was confirmed by clinical exminations during the follow up period and at the time of the last visit. In a few patients echocardiography was performed to document the valvular lesion.

Results 38 (19 Male, 19 female) patients with median age of 14.5 years (range 5-36) were studied. All patients presented with polyarthritis. Carditis occured in 14 (37\%) patients. Mitral regurgitation alone in 10 , and in combination with aortic regurgitation and stenosis in 2, aortic stenosis and regurgitation alone in 2.

Secondary prophylaxis (SP) was recommended and patients were followed for a mean period of 6 (range 1-15) years.

No recurrences were seen in $22(56 \%)$ patients who remained on SP, whereas 6 of 16 noncompliants with SP showed recurrences. five attacks of recurrences observed in 6 noncompliant patients with carditis.

Among the 14 patients with carditis, residual valvular disease persisted in all 5 cases of carditis who had recurrences and 3 of 9 patients without recurrence.

Conclusion RF remains a significant health problem in the developing countries and disease recurrence is an important risk factor for persistence of residual heart disease, so strict adherence to SP is indicated

\section{REFERENCES}

1 David L. Diagnosis and treatment of rheumnatic fever. Arch Pediatre. 1998:5:681-6

2 Abbag F, Benjamin B, Kardosh MM, Al-Barki A. Acute rheumatic fever in southern saudi arabia. East Afr Med J. 1998;75:279-81

3 Richmond $P$, Harris L. Rheumatic fever in the Kinberley region of Western Australia. I Trop Pediatr. 1998:44:148-52

4 American Heart Association. Jnes criteria (revised) for guidance in the diagnosis of rhumatic fever. Circulation 1984;69:204A-208A 